\title{
Covid-19: ibuprofen can be used for symptoms, says UK agency, but reasons for change in advice are unclear
}

\author{
Ingrid Torjesen
}

London, UK

UK medicines agencies have changed their advice on ibuprofen to say that the drug can be used to treat patients with symptoms of covid-19, although the evidence that prompted the revision has not been made public.

The change follows a review by the Commission on Human Medicines' expert working group on covid-19 which, along with previous reviews of evidence, concluded that there is currently insufficient evidence to establish a link between use of ibuprofen, or other non-steroidal anti-inflammatory drugs (NSAIDs), and contracting or worsening of covid-19. ${ }^{1}$

The group's review has not been published, but prompted the Medicines and Healthcare Products Regulatory Agency (MHRA), NHS England, and the National Institute for Health and Care Excellence (NICE) to update their advice to say that patients can take paracetamol or ibuprofen for symptoms of covid-19, such as fever and headache. ${ }^{2}$

This is a change to NICE's recommendation on 3 April that paracetamol should be used in preference to NSAIDs for managing fever in patients with suspected covid-19 until more evidence is available. ${ }^{3}$

Paul Little, professor of primary care research at the University of Southampton, has written an editorial on the use of NSAIDs in covid-19 patients. ${ }^{4} \mathrm{He}$ expressed concern that neither the rationale nor the evidence base for the new advice had been published.

"The whole thing should be much more explicit in order to allow sensible discussion and proper critique," he told The BMJ. "I'm not cynical by nature but the thought that there might be other agendas did occur to me, but I suspect it is just that they are undervaluing the case control evidence."

Concerns about the safety of NSAIDs for treating symptoms of infections have been brewing for some time. Last May the European Medicines Agency began a review of the NSAIDs ibuprofen and ketoprofen prompted by evidence from France that it could worsen varicella and some bacterial infections. ${ }^{5}$

Concerns about use of ibuprofen with covid-19 were heightened by a tweet from France's health minister Oliver Veran on 14 March warning that taking anti-inflammatory drugs such as ibuprofen could aggravate the infection and advising patients to take paracetamol instead. ${ }^{6}$ This prompted panic buying of paracetamol and pharmacies now struggle to obtain stock.
While the expert working group's conclusion that there is currently insufficient evidence to establish a link between use of ibuprofen and susceptibility to contracting covid-19 or the worsening of its symptoms is "clearly true," Little said, there is "equally no good evidence from the current pandemic that it works for the symptoms of covid-19."

He warned, "There is a danger of harm from this advice if more people start taking ibuprofen regularly for their

symptoms-which they are implicitly encouraging. But I do hope I'm wrong."

In its guidance updated on 14 April, NICE says that policy decisions on whether NSAIDs should be used in covid-19 will need to consider studies of the use of NSAIDs for other acute respiratory tract infections and pharmacoepidemiological studies. $^{7}$

"The available evidence suggests that, although the anti-inflammatory effects of NSAIDs reduce acute symptoms (such as fever), they may either have no effect on, or worsen, long term outcomes, possibly by masking symptoms of worsening acute respiratory tract infection. Further evidence is needed to confirm this, and to determine whether these results also apply to infections such as covid-19."

The change of policy suggests that the Commission on Human Medicines' expert working group had more up-to-date data available, perhaps data from NSAID use in covid-19, or took other factors into account such as a shortage of paracetamol. But neither the MHRA or NICE would identify the reason for the change of policy.

A spokesperson for the MHRA said that the expert working group considered the available evidence on the use of ibuprofen and other NSAIDs and the outcome of worsening of infections, including from published studies. "The evidence considered by the expert working group did not include information on the availability of ibuprofen or other drugs and did not include representations from companies holding licences for ibuprofen or other drugs," they said.

In a statement, NICE said it "could not find any evidence to suggest whether acute use of NSAIDs is related to increased risk of developing covid-19 or increased risk of a more severe illness. NHS England has developed a commissioning policy for acute use of NSAIDs for people with or at risk of covid-19. As this is a rapidly changing situation, we're regularly reviewing 
our guidance and will update in line with the best available evidence."

\section{Clarification: On 20 April we added a phrase to Paul Little's quotation that} had been omitted.

1. Medicines and Healthcare Products Regulatory Agency, Commission on Human Medicines. Commission on Human Medicines advice on ibuprofen and coronavirus (covid-19). 14 April 2020. www.gov.uk/government/news/commission-on-human-medicines-advice-onibuprofen-and-coronavirus-covid-19.

2 Powis S, Leng G, Raine J. Ibuprofen and coronavirus (covid-19). 14 April 2020. www.cas. mhra.gov.uk/ViewandAcknowledgment/ViewAttachment.aspx?Attachment_id=103524.
3 Torjesen I. Covid-19: NICE advises against using NSAIDs for fever in patients with suspected cases. BMJ 2020;369:m1409. 10.1136/bmj.m1409 32253225

4 Little P. Non-steroidal anti-inflammatory drugs and covid-19. BMJ 2020;368:m1185. 10.1136/bmj.m1185 32220865

5 European Medicines Agency. EMA gives advice on the use of non-steroidal anti-inflammatories for COVID-19. March 2020. www.ema.europa.eu/en/news/ema-givesadvice-use-non-steroidal-anti-inflammatories-covid-19

6 Day M. Covid-19: ibuprofen should not be used for managing symptoms, say doctors and scientists. BMJ 2020;368:m1086. 10.1136/bmj.m1086 32184201

7 NICE. Acute use of non-steroidal anti-inflammatory drugs (NSAIDs) for people with or at risk of COVID-19. April 2020. www.nice.org.uk/advice/es23/chapter/Key-messages.

Published by the BMJ Publishing Group Limited. For permission to use (where not already granted under a licence) please go to http://group.bmj.com/group/rights-licensing/ permissions 